\title{
Modeling and optimization of the decision- making process in the transport system
}

\author{
Mihail Mochalin ${ }^{1}$, Sergey Mochalin ${ }^{1, *}$, Grigory Levkin ${ }^{2}$, Mariya Kasper $^{1}$ \\ ${ }^{1}$ Siberian State Automobile and Highway University, Mira 5, Omsk, 644080, Russia \\ ${ }^{2}$ Omsk State Transport University, 644046, Marx av., 35, Omsk, Russia
}

\begin{abstract}
The article deals with the issue of constructing an intellectual system for managing the transport system for the delivery of goods by road in cities. The authors develop the algorithm for constructing schedule the work of all participants of the transport system. It can be used to build an operational plan for the delivery of goods and the subsequent management of the transport system.
\end{abstract}

\section{Introduction}

Effective management of the transport system is impossible without the use of economic and mathematical methods (EMM) $[1,3,4]$. They significantly improve the productivity of its operation and reduce unproductive costs $[2,5]$. It is here, in the transport systems of goods delivery, an effective solution to the tasks of organizing and managing the delivery process is required. It is here, efficiency is making for all participants in the system (producer-carrierconsumer) $[7,8]$.

When in the transport system there are several cars, it may turn out that most of the time they can spend in downtime, waiting for loading and unloading. So, that is why they are not fulfill the planned volume of freight transportation [6]. This is more evident in vehiclesaturated transport systems [12]. In order to optimize the operation of the transport system, it is necessary to streamline the arrival of vehicles to the cargo points and minimize the waiting time for loading and unloading at a freight terminals that has the maximum rhythm of service.

\section{Literature review}

In work [11] it is noted the necessary of solving the problem of ordering the arrival of cars in freight terminals. It needs for exclude downtime in anticipation of operations, both for cars and freight terminals themselves. Based on the provisions of the theory of operations research, the authors have revealed the patterns of appearance of the queue. They noted that "for the emergence of a queue it is enough that receipts of claims occur at irregular intervals. A queue can also occur at a constant service time and the receipt of claims at regular intervals, if the service duration exceeds the arrival time interval". Thus, the dependence of the

*Corresponding author: mochalin_sm@mail.ru 
formation of the queue on the ratio of the interval of arrival cars and the rhythm of their service at the freight terminals was noted.

From the foregoing, it follows that for improving the management of transport systems, it is necessary to develop provisions of constructing the schedule for all participants in the system with ensuring the fulfillment of the task with the least resource costs.

In $[9,10]$, the authors propose the approach with operations of loading coordinated in time and the information support, but they do not consider the system comprehensively as a whole.

In this connection, the authors propose a new approach to the development of an intellectual system for managing the transport system for the delivery of goods, based on the constructing schedule and organizational support for the management of the operation of the transport system. The algorithm of the procedure is presented in the form of the following blocks.

\section{Proposed algorithm for constructing schedule}

Block 1. Input of the initial information

To perform the calculations, the following information is required:

$>$ distance between the points of loading and unloading in the systems $\left(1_{\mathrm{fj}} ; 1_{\mathrm{nfj}}-\right.$ the mileage of the vehicle, respectively, with freight and without freight (no freight) on the $\mathrm{j}$-th link of the route (for each transport system) $(\mathrm{j} \in 1 ; \mathrm{m})), \mathrm{km}$;

$>l_{z 1}, l_{z 2}$ - the values of zero runs, respectively, when departuring and returning to the enterprize on the $\mathrm{j}$-th link of the route (for all systems), $\mathrm{km}$;

$>\mathrm{V}_{\mathrm{tj}}$ - average technical speed of cars on the $\mathrm{j}$-th link of the route, $\mathrm{km} / \mathrm{h}$.;

$>t_{\mathrm{lj}} ; t_{\mathrm{ulj}}$ - the time required for loading and unloading operations at the $\mathrm{j}$-th link of the route, h.;

$>\mathrm{x}_{\mathrm{lj}} ; \mathrm{x}_{\mathrm{ulj}}$ - the number of posts, respectively, loading and unloading at the $\mathrm{j}$-th link of the route, units;

$>\mathrm{T}_{\mathrm{s}}$ - planned time of the system operation during the day, h.;

$>\mathrm{Q}_{\mathrm{ftj}}$ - daily volume of the freight transportation presented for transportation on the $\mathrm{j}$-th route for the planned period, tons;

$>\gamma_{\mathrm{j}}$ - static coefficient of load capacity of the rolling stock on the $\mathrm{j}$-th link of the route;

$>\mathrm{q}$ - carrying capacity of rolling stock, tons;грузоподъемность подвижного состава, $\mathrm{T}$;

$>\mathrm{T}_{\mathrm{b}}$ - time of the beginning of the operation of the transport system, $\mathrm{h}$.

Block 2. Calculation the indicators of the transport system.

In this block, the calculation of technical and operational indicators of work in each transport system is made. The procedure for calculation is presented in [12].

Block 3. Formation of a consolidated matrix of indicators of work for all transport systems.

From the results obtained in Block 2 we form the matrix for all systems:

$>\mathrm{A}_{\mathrm{w}}$ - the number of vehicles working in the system, units;

$>\mathrm{t}_{\mathrm{o}}$ - turnaround time (without downtime of cars in anticipation of loading and unloading operations), h.;

$>\mathrm{t}_{\mathrm{ozh}}$ - total downtime of each car in waiting of loading and unloading in the system for the time of operation in this system, h.;

$>\mathrm{Z}_{\mathrm{e}}^{\mathrm{p}}$ - the possible number of rides that a car can perform while working in the system for the planned time of tour of duty (время в наряде), units;

$>\mathrm{Z}_{\mathrm{e}}^{\mathrm{f}}-$ the fact number of rides that the car will perform while working in the system, units;

$>\mathrm{Q}$ - volume of freight transportation, tons;

$>\mathrm{P}-$ turnover of goods, t.-km; 
$>\mathrm{L}_{\mathrm{t}}$ - total daily mileage of the car, $\mathrm{km}$;

$>\mathrm{T}_{\mathrm{p}}$ - planned time of the tour of duty into account the rhythm of the work of the transport system, h.;

$>\mathrm{T}_{\mathrm{f}}$ - fact time of the tour of duty, h.;

$>\Delta \mathrm{T}_{\mathrm{p}}$ - remaining time of the tour of duty, $\mathrm{h}$.

Block 4. Identification of the minimum fact time of tour of duty for vehicle in all transport systems

From the column with the value (Tf) - "fact time of the tour of duty" of the formed matrix (block 3 ) the minimum value is chosen using the "minimum by column" method - Tfmin.

Block 5. Enumeration of transport systems.

In this block, all transport systems (TS) are moved one by one.

$\mathrm{i}$ - the number of the transport system, $\mathrm{i}=1,2, \ldots, \mathrm{TS}$.

Block 6. Enumeration of cars working in the transport system.

In this block, the cars that are working in the system are moved one by one.

$\mathrm{j}-$ the number of cars working in the system, $\mathrm{j}=1,2, \ldots$, Aw.

Block 7. Identification of "significant remaining time of tour of duty".

Significant remaining time of the tour of duty are found by comparing remaining time of the tour of duty $\Delta \mathrm{Tp}$ (block №3 column $\Delta \mathrm{Tp}$ ) with the minimum time of the tour of duty Tfmin (block №4).

«Significant remaining time of the tour of duty» $(\Delta \mathrm{Tpz})$ is the remainder, which is greater than or equal to the minimum fact time of the tour of duty from all transport systems:

$$
\Delta \mathrm{T}_{\mathrm{p}}^{\mathrm{z}} \geq \mathrm{T}_{\mathrm{f}}^{\min }
$$

Compare the remaining time of the tour of duty for the vehicle operating in the given transport system with the minimum fact time of the tour of duty. If condition (1) is fulfilled, the remainder is significant and block 10 works, otherwise block 9 works.

Block 8. All transport systems viewed?

Verification of the condition: have all available transport systems been reviewed? $(i=$ TS). If yes, no significant balances are found and calculations are stopped; if not - then the block number 5 works.

Block 9. Stop calculations.

All calculations are stopped.

Block 10. Formation of a matrix of "significant remainders".

A matrix of "significant remainders" is formed, which includes:

$>$ the designation of the system;

$>\mathrm{A}_{\mathrm{w}}{ }^{\mathrm{z}}$ - cars that have "significant remaining time of the tour of duty" operating in the transport system;

$>\Delta \mathrm{T}_{\mathrm{p}}^{\mathrm{z}}-$ "significant remainders of the tour of duty".

Ordinal numbers of cars with "significant remainings" are remembered, and all further calculations are conducted only with them.

Block 11. Determination of the intervals of movement of vehicles in the transport system.

The interval of motion is:

$$
\mathrm{I}_{\mathrm{mi}}=\mathrm{t}_{\mathrm{o}} / \mathrm{A}_{\mathrm{W}}
$$

where to - turnaround time (without downtime of cars in anticipation of loading and unloading operations), h.;

Ae - the number of vehicles working in the system, units.

to and Ae is presented in Block 3.

Block 12. The definition of transport systems in which cars have "significant remaining time of the tour of duty". 
In this block, all transport systems are searched, and the identification of systems in which cars have "significant remaining time of the tour of duty".

$\gamma$ - transport systems, in which cars have "significant remaining time of the tour of duty".

Block 13. Definition of cars that have significant remaining time of the tour of duty

Numbers of cars working in the transport system are sorted out.

$\beta$ - cars having significant remaining time of the tour of duty, working in $\gamma$-transport systems.

Block 14. Comparison of the interval and rhythm.

This block reveals the oversaturation of the transport system by comparing the interval of motion Im (block 11) and rhythm of the system - a period of time between the endings of the loading of two consecutive arriving cars. It is calculated as the ratio of the loading time of one car to the number of loading posts (block 2)

$$
\mathrm{I}_{\mathrm{m}}<\mathrm{R}
$$

where Im - interval of motion, h.; R - rhythm of the system, h.

If condition (3) is fulfilled, block 15 works, otherwise block 17 works.

Block 15. Is the transport system oversaturated?

The oversaturated transport system is the system in which the interval of vehicle motion is less than the rhythm of the system. The peculiarity of this system is that cars will stand downtime waiting for operations in the "narrow link" of the transport system.

Block 16. The exclusion of a car that leads the transport system into a oversaturated state.

The number of vehicles operating in a oversaturated transport system is reduced by one unit. The transport system becomes saturated.

$$
\mathrm{A}_{\mathrm{w}}=\mathrm{A}_{\mathrm{W}}-1
$$

Block №17. Comparing the intervals and rhythm.

$$
\mathrm{I}_{\mathrm{m}}=\mathrm{R}
$$

If the interval of motion is equal to the rhythm, block 18 works, if not, block 20 works.

Block 18. The transport system is saturated.

A saturated transport system is that system in which the interval of vehicle movement is equal to the rhythm of the operation of the transport system.

Block 19. Determination the moments of time for "spliting" the schedule.

In saturated systems, the moments of time in which it is possible to split the schedule of vehicles in the system are determined by the following formula:

$$
\mathrm{T}^{\mathrm{r}}=\mathrm{T}_{\mathrm{b}}+\mathrm{R} \cdot(\mathrm{j}-1)+\mathrm{t}_{0} \cdot \mathrm{k}
$$

where $k$ - the ordinal number of ride of the $\mathrm{j}$-th vehicle of the $\gamma$-transport system, $\mathrm{k}$ $=0,1, \ldots, \mathrm{Z}_{\mathrm{e}}^{\mathrm{p}}$

Block 20. The transport system is unsaturated.

An unsaturated system is that system in which the interval is greater than the rhythm of the system. There is no waiting time for vehicles.

Block 21. Definition of free windows of posts.

In unsaturated transport systems, time intervals are defined where loading posts are free from cars:

$$
\begin{aligned}
& \text { from } \mathrm{T}_{\mathrm{b}}+\mathrm{R} \cdot(\mathrm{j}-1)+\mathrm{t}_{0} \cdot \mathrm{k} \\
& \text { to } \mathrm{T}_{\mathrm{b}}+\mathrm{t}_{0} \cdot(\mathrm{k}+1)-\mathrm{t}_{1}
\end{aligned}
$$

where $\mathrm{tl}$ - the time required for loading, $\mathrm{h}$. 
Block 22. Formation of a matrix of "free windows" of loading posts and moments of time for "spliting".

From the indicators presented in blocks 19 and 21, we form the matrix of "free windows".

Block 23. Determination of the end time of vehicles in the transport system.

The end time of work for the $\mathrm{j}$-th car in the system is determined by:

$$
\mathrm{T}_{\mathrm{e}}=\mathrm{T}_{\mathrm{b}}+\mathrm{R} \cdot(\mathrm{j}-1)+\mathrm{T}_{\mathrm{fj}}-\mathrm{l}_{\mathrm{hba}} / \mathrm{V}_{\mathrm{t}}
$$

where $\mathrm{Tf} j$ - the fact time of the tour of duty for the $\mathrm{j}$-th car, h.; lhba - mileage made by the car from the unloading point to the loading point at the last turn, $\mathrm{km}$.

Block 24. Determine the time spent on the runs between points.

The cost of time for runs between points of loading and unloading is determined by the formula [2]:

$$
\mathrm{T}_{\text {per }}=1_{\mathrm{AB}} / \mathrm{V}_{\mathrm{t}}
$$

The results of calculating the time spent on the runs between points of loading and unloading are presented in the form of a table.

Block 25. Determination of the current time after moving cars from one transport system to another.

Current time after moving the car from one system to another:

$$
\mathrm{T}_{\text {tekj }}=\mathrm{T}_{\mathrm{ej}}+\mathrm{T}_{\text {perBxAy }}
$$

where Tej - the end time of work for the $\mathrm{j}$-th car in the system "X", h; TperBxAy - time of moving from the "X" system to the "Y" system, h. The "X" system is the system from where the car moves. System "Y" is the system where the car moves. All variants of moving a car from one transport system to another are considered. The results of the calculation are reduced to a table.

Block 26. Determination of the current time when the loading-unloading posts finish its work.

$$
\mathrm{T}_{\mathrm{p}}{ }^{\prime}=\mathrm{T}_{\mathrm{b}}+\mathrm{T}_{\mathrm{prj}}
$$

where Tprj - planned time of the tour of duty of the $\mathrm{j}$-th car without taking into account the rhythm (the operating time of the system), h.

Block 27. Determination of the fact remaining time of cars, taking into account the move from one system to another.

$$
\Delta \mathrm{T}_{\text {nfbxAy }}=\mathrm{T}_{\mathrm{p}}{ }-\mathrm{T}_{\text {tekj }}
$$

The results of the calculation are summarized in a table.

Block 28. Determine the number of intervals in which cars can arrive in the transport system and perform scheduled work.

$$
\mathrm{n}=\left(\mathrm{Ze}_{\mathrm{e}}^{\mathrm{p}}-\mathrm{Z}_{\mathrm{e}}^{\mathrm{f}}\right)+1
$$

Block 29 and Block 30. Checking the conditions for the move.

A car arriving from another transport system " $\mathrm{X}$ " should carry the volume of freight tranportation planned for the $\mathrm{j}$-th vehicle of the "U" system.

To do this, it is necessary that the fact remaining time of the moving car of the system "X" should be greater than or equal to the fact time of the car of the "U" system, taking into account the fact that the moving car should arrive to the system to the maximum possible moment of sending.

$$
\Delta \mathrm{T}_{\mathrm{nfxy}} \geq \mathrm{T}_{\mathrm{fj}}
$$


where $\Delta \operatorname{Tnfxy}--$ fact remainders of the time for the $\beta$-car after making the move from the "X" system to the "Y" system (see block 27), h; Tfj - the fact time of tour of duty for the $\mathrm{j}$-car (for which the volume is planned to be performed) (see block 5), $\mathrm{h}$.

$$
\mathrm{T}_{\text {prib }}{ }^{\max } \geq \mathrm{T}_{\text {tek } \beta}
$$

where $\mathrm{T}_{\text {prib }}{ }^{\max }$ - the maximum possible time of departure, when the car that arrived from the system "X" to the "Y" system can arrive for loading (see block 8), taking into account the moment of the departure (see block 28), $\mathrm{h} ; \mathrm{T}_{\text {tek } \beta}$ - current time after the arrival of the $\beta$-th vehicle in the "Y" system (see block 10);

Ttek $\beta$ - current time after the arrival of the $\beta$-th vehicle in the "Y" system (see block 10);

The moving is made only if both conditions (15) and (16) are met. If the conditions are met, then block 31 works, otherwise block 9 .

Block 31. Selection criteria for the move.

The main and additional criteria for performing the move are selected. The main criterion can be:

Block 32. Formation of the matrix of the main criterion for moving.

The matrix of the main criterion is formed.

Block 33. Definition of an additional criterion for moving.

$>$ 2. maximum

$>\mathrm{Q}$ - volume of freight transportation, tons;

$>\mathrm{P}$ - turnover, tkm;

$>$ D - profit, y.e.; etc.

$>$ the minimum

$>$ lc - daily mileage, $\mathrm{km}$;

$>\mathrm{Ze}$ - number of rides, units;

$>\quad \mathrm{C}$ - costs, y.e. etc.

An additional criterion for moving can be minimum of time for moving and downtime for $\beta$-car arrival from the system " $\mathrm{X}$ " into the "Y" system

$$
\mathrm{T}_{\text {per }}+\mathrm{t}^{\prime}{ }_{\text {ozh } \beta} \rightarrow \min
$$

Block 34. Determination of the downtime for loading and unloading operations after moving.

$$
\mathrm{t}_{\mathrm{ozh} \beta}^{\prime}=\mathrm{T}_{\mathrm{pr}} \text { bliz }-\mathrm{T}_{\text {tek } \beta}
$$

where $\mathrm{T}_{\mathrm{pr}}{ }^{\text {bliz }}$ - the closest moment of time when the $\beta$-th vehicle arriving from another system can start loading (it is taken from Block 8 in relation to the current time after the car arrives at another system $\left.\mathrm{T}_{\text {tek } \beta}\right), \mathrm{h}$.

Block 35 . Formation of a matrix of an additional criterion for completing the moving.

To the obtained values of the waiting time (see block \# 34) we add the time of moving Tper (see block 24) and form the matrix of the additional criterion.

Block 36. The choice of options for moving from the " $\mathrm{X}$ " system to the "Y" system.

The choice is made as follows (method of SibADI):

1. A single value (the number "1") is assigned for all possible variants of moving, the number " 0 " is assigned for impossible variants of moving. The matrix of possible movings is constructed.

2. Finding the sum of possible variants of moving to the system "Y" (the sum of units for each line).

3. Choosing the system with the least amount of possible moviings from all the identified systems "Y" using the "minimum by column" method.

4. If there are two or more such systems (the amounts are equal), then we choose the option of moving, where the main criterion for moving is the smallest. 
5. Exception from the array of possible variants of moving, variants of the already considered systems " $\mathrm{X}$ " and "Y". In the matrix of possible movings, the value in the columns and rows for these systems is assigned " 0 ".

6. Are all possible variants of moving considered? If not, go to step 1 . If yes, stop the selection.

Block 37. Rectification of technical and operational indicators for the operation of cars and transport systems.

$$
Z_{\text {ex }}^{\prime}{ }^{\text {fact }}=Z_{\mathrm{ex}}{ }^{\text {fact }}+Z_{\mathrm{ey}}{ }^{\text {fact }}
$$

where $Z_{\text {ex }}^{\prime}{ }^{\text {fact }}$ - refined fact number of rides of a moving car, units; $Z_{\mathrm{ex}}{ }^{\text {fact }}, Z_{\mathrm{ey}}{ }^{\text {fact }}-$ the number of rides of the moving car in the " $\mathrm{X}$ " system and the number of rides that need to be performed in the "Y" system after moving, respectively, units. (see Block 5).

Volume of freight transportation:

$$
\mathrm{Q}_{\mathrm{x}}^{\prime}=\mathrm{Q}_{\mathrm{x}}+\mathrm{Q}_{\mathrm{y}}
$$

where $\mathrm{Q}_{\mathrm{x}}, \mathrm{Q}_{\mathrm{y}}$ - volumes of freight transportation in the system «X» and «Y».

Turnover:

$$
\mathrm{P}_{\mathrm{x}}^{\prime}=\mathrm{P}_{\mathrm{x}}+\mathrm{P}_{\mathrm{y}}
$$

Daily mileage:

$$
\mathrm{L}_{\mathrm{cx}}^{\prime}=\mathrm{L}_{\mathrm{cx}}+\mathrm{L}_{\mathrm{per}}-\mathrm{L}_{\mathrm{z} 2 \mathrm{x}}^{\mathrm{I}}+\mathrm{L}_{\mathrm{z} 2 \mathrm{x}}^{\mathrm{II}}+\left(\mathrm{L}_{\mathrm{cy}}-\mathrm{L}_{\mathrm{z} 2 \mathrm{y}}\right)
$$

where $\mathrm{L}_{\mathrm{cx}}$ - initial total mileage of the moving car, $\mathrm{km} ; \mathrm{L}_{\mathrm{z} 2 \mathrm{x}}-$ zero mileage of the moving car according to the first variant (mileage from the last point of unloading to the enterprise), $\mathrm{km}$; $\mathrm{L}_{\mathrm{per}}$ - distance of moving, $\mathrm{km} ; \mathrm{L}_{\mathrm{z} 2 \mathrm{x}}$ - the second zero run of the moving car according to the second variant, $\mathrm{km} ; \mathrm{L}_{\mathrm{cx}}$ - daily mileage of the car for which the planned volume is carried out, $\mathrm{km} ; \mathrm{L}_{\mathrm{z} 2 \mathrm{y}}$ - the second zero run of the car for which the planned volume is carried out, $\mathrm{km}$.

$$
\mathrm{T}_{\mathrm{fx}}^{\prime}=\mathrm{T}_{\mathrm{fx}}+\mathrm{T}_{\mathrm{per}}+\mathrm{t}_{\mathrm{ozh}}-\mathrm{L}_{\mathrm{z} 2 \mathrm{x}}^{\mathrm{I}} / \mathrm{V}_{\mathrm{t}}+\mathrm{L}_{\mathrm{z} 2 \mathrm{x}}^{\mathrm{II}} / \mathrm{V}_{\mathrm{t}}+\left(\mathrm{T}_{\mathrm{fy}}-\mathrm{L}_{\mathrm{z} 2 \mathrm{y}}\right)
$$

where $\mathrm{T}_{\mathrm{fx}}, \mathrm{T}_{\mathrm{fy}}$ - the actual time of the moving car, respectively, in its system and in the system in which the move is made, $h$; $T_{\text {per }}$ - time of moving (see Block №6), $h$; $t_{\text {ozh }}$ - waiting time for loading and unloading operations upon the arrival of the car in the next system (see Block 16), h.

Remaining time of the tour of duty of car:

$$
\Delta \mathrm{T}_{\mathrm{px}}=\mathrm{T}_{\mathrm{pi}}-\mathrm{T}_{\mathrm{fx}}^{\prime}
$$

where $\mathrm{T}_{\mathrm{pi}}-$ planned time of the tour of duty for the $\mathrm{i}$-th car (which make the move) taking into account the rhythm, h.

After refinement of technical and operational indicators, turn to Block 3 and repeat the calculations.

\section{Results}

The foregoing provisions are the basis for the creation of an intellectual management system for freight road transport.

As a result of modeling, the following documents are formed:

1) for the operator (logistics provider) - the timetable for the operation of the transport system;

2) for the carrier, the schedules of each car for the whole shift; 
3) for freight terminals - the schedule of work of each point of loading and unloading, as well as a table "intervals of idle time of cargo equipment in anticipation of cars." These output forms are the basis for further operational management of the delivery of goods and decisionmaking in the event of a failing situation.

Users of this system are: the organizer of transportation, carriers, managing the delivery of goods in cities.

\section{Conclusions}

The developed measures made it possible to solute of issues of management in transport systems by scientific reasonably approach. The introduction of scientific provisions in the practice of managing the delivery of goods by "OmskVodokanal" allowed to reduce the number of cars for 4 units with the same volume of transportation and ensure a reduction in the cost of one ton-kilometer by 0.09 rubles.

The result obtained indicates that the provisions discussed allow for more effective management of delivery compared to existing practices. The work of the four cars will allow to receive additional income.

\section{References}

1. H. Thorisson, D.C. Hendrickson, T.L. Polmateer, J.H. Lambert, Journal of Risk and Uncertainty in Engineering Systems, Part B: Mechanical Engineering 5-1, 011007 (2019) DOI:10.1115/1.4040918

2. M. Rida, Arabian Journal for Science and Engineering 39(11), 8395-8408 (2014) DOI:10.1007/s13369-014-1328-8

3. J.X. Cao, D.-H. Lee, J.H. Chen, Q. Shi, Transportation Research Part E: Logistics and Transportation Review 46(3), 344- 353 (2010) DOI: 10.1016/j.tre.2009.08.012

4. B. Dragović, N.K. Park, Z. Radmilović, Maritime Policy and Management 33(3), 281 299 (2006) DOI: 10.1080/03088830600783277

5. Y. Xu, Q. Chen, X. Quan, Annals of Operations Research 192(1), 123-140, DOI: 10.1007/s10479-010-0820-0

6. N. Huynh, N. Hutson, Transportation Research Record, 41-49 (2008) DOI: 10.3141/2066-05

7. J. Liu, M.-F.F. Siu, M. Lu, Proceedings - Winter Simulation Conference 7822358, 32693280 (2017) DOI:10.1109/WSC.2016.7822358

8. O. Nikiforov, G. Levkin, S. Mochalin, R. Simak, K. Dzyubina, Transport Problems2015, VII International Scientific Conference. Silesian University of Technology, 391407 (2015) DOI:10.20858/tp.2016.11.2.4

9. B.L. Geronimus, Economic and mathematical methods in planning for road transport (Transport, Moscow, 1982)

10. A.P. Kozhin, V.N. Mezentsev, Mathematical methods in the planning and management of freight road transport (Transport, Moscow, 1994)

11. A. Kofman, A. Anri-Laborder, Methods and models of operations research. Integer programming (Mir, Moscow, 1977)

12. M.S. Mochalin, N.G. Pevnev, Topical issues of scientific research: collective monograph, https://elibrary.ru/item.asp?id=26081425 
